\title{
Universalism and Utilitarianism, Two Worlds Apart or Inextricably Linked?
}

\author{
Tan Seng Teck ${ }^{1}$, Liau Chee $\mathrm{How}^{2}$, Nanthakumar Karuppiah ${ }^{3}$ \& Chang Jau $\mathrm{Ho}^{3}$ \\ ${ }^{1}$ School of Commerce, University of Wollongong, Malaysia Campus, Malaysia \\ ${ }^{2}$ Faculty of Business and Law, Deakin University Melbourne, Australia \\ ${ }^{3}$ University of Hertfordshire Centre, INTI International College, Malaysia \\ Correspondence: Tan Seng Teck, School of Commerce, University of Wollongong, Malaysia Campus, Subang \\ Jaya, Malaysia.
}

Received: December 13, 2017 Accepted: January 5, 2018 Online Published: February 3, 2018

doi:10.5539/jms.v8n1p13ＵRL: https://doi.org/10.5539/jms.v8n1p13

\begin{abstract}
Most authors and researchers consistently perceive ethics as being invariably divided into two clearly discernible divisions. The Kantian categorically imperative and universalistic divinity prescribes a somewhat non-negotiable and positivistic duty based maxim that guide the actualization of altruism. Conversely, the contemporary but more relative utilitarian approach advocates that an action that produces the greatest wellbeing of good for the greatest number is undeniably the ethical one. Clearly, it makes little sense and very negligible contribution to literature if corporations are continuously misled to believe that such strict and fervent dichotomy exist. On one hand, business firms in this globalized era are increasingly pressured to comply with emerging universalistic international laws. On the other, business firms cannot remain entirely altruistic. Corporations greatly need the flexibility and capability to relate dissimilar cultural contents and moral distorts. This paper maintains that there is an inextricable link between universalism and utilitarianism. The association between the two is at best complex and intricate. Business firms commonly usurp a utilitarian slant where relativity and ability to adapt is pivotal. However, a firm is estopped from usurping utilitarianism if a firm's conduct falls below the threshold and minimum content of morality. This would immediately instigate a punctuated equilibrium in the firm triggered through a tsunamic impact, causing the firm to refresh into a universalistic mode. This punctuated equilibrium is frequently activated by external factors that are adequately vigorous to refresh and reset the moral values of a firm. Consider Shell's defensive posture over the Brent Oil Spar allegation which left the firm with diving stock value and tarnished branding. Shell since then has taken a more Kantian receptive posture of apologizing for their catastrophic mistakes which resembled a renewed commitment to the betterment of human kind. This paper contributes to better the understanding of this ethical transition that firms might experience in their course of organization life cycle and how it can be managed tactfully.
\end{abstract}

Keywords: universalism, utilitarianism, punctuated equilibrium

\section{Utilitarianism and Universalism-Two Worlds Apart?}

It has often been an intellectual norm for researchers and authors to classically characterise ethics into two divisions of normative notions. These different cohorts of normative theories are often termed as "rival ethical principles" (Shaw et al., 2013), coined as "convenience" (Shaw et al., 2010) and most literatures fittingly label them as being the "consequentialist" and "non-consequentialist" theorem. Of course, the contribution of this simplistic division of normative ethics is that it furnishes business firms with clear standards to benchmark an organisation's business activity. Shaw (2013) for example, indicates that such division is a common and simplistic practice. It contributes to resolving specific and general ethical dilemmas. Shaw mentioned that:

It is a common practice to group these theories as consequentialist and non-consequentialist. This is simply a way of separating those theories that are concerned primarily with outcomes (or consequences) and those theories that are primarily concerned with particular or general principles or rules on which to base our decisions or resolve dilemmas (p. 58) [Emphasis added]

While this positivistic division of ethics is easy to understand and apply, the contributions of this approach are fundamentally hindered by two fundamental challenges. Firstly, the positivistic approach ignores the fact that 
corporations do not exist in vacuum. On the contrary, corporations are deeply "grounded" in a society. Corporations' responses and interpretation to ethical concerns are predisposed by contextual business environments. Positivistic approach lacks the structural ability to understand this labyrinth of interactions between the firm and its externalities. Secondly, it misleads firms to believe that there is only "one best way" of measuring ethics. Firms are misguided to undertake one perspective in the sacrifice of the other. It is from these two limitations that this paper takes an alternative approach. This paper argues that the values of ethics are not mutually exclusive but on the contrary mutually inclusive. This paper aims to precisely examine the point of convergence and mutual inclusivity between utilitarianism and universalism. Instead of viewing universalism and utilitarianism as separate notions in ethics, business firms must understand the cyclical influence of ethics.

Indeed, a firm is fundamentally assumed to usurp a utilitarianism business model. This assumption coincides with the "game of business" (Albert Carr, 1968). Ethical relativism dictates that a business firm should make economically profitable rather than morally responsible decisions. However, business firms cannot manipulate this relative values freely. They are constantly monitored and supervised by external stakeholders. Corporations cannot breach the minimum content and threshold of morality. If a firm indeed breaches the minimalist threshold of universalism, termed here as punctuated equilibrium, the firm might experience a "backlash" which in turn unleashes the fullest uproar of legal, political and social repercussions. This in turn puts the firm in immense jeopardy and adverse adjudication. These tsunamic events and repercussions might reset the values of the firm. It can reverse the polarity of the firm's ethical position and steers the firm towards a purely universalistic one. In conjunction to this view, this paper aims to explore this inextricable link between utilitarianism and universalism using a qualitative approach.

\section{A Theoretical Overview}

Universalism is a purely deontological or duty based theory on morality. This is widely known as a non-consequentialist model. Immanuel Kant (1724-1804) argues that the approach and application of morality must be consistent, non-contradictory and based on good will. Kant maintains that the maxims of morality are categorically imperative. Moral values should be pure and without contradictions. By this, Kant asserts that one should treat "humanity as an end and never a means to an end". By this also, Kant meant that a rule ought to be universally accepted. A rule should be dismissed if it lacks universal acceptance. Weiss (2009) extended this value to include two additional factors. Firstly, one can only behave in the same way he wants others to delight him. Secondly, one should always behave in all ways and manners with respect to others, in the same way the actor would want others to respect him.

One of the main advantage and strength of Kantian's universalistic approach is the consistency in applying moral values. Any actions and behaviours prompted by good will is deemed moral and such actions exalt the values of humanity. Kantian's values are a fervently benchmarked against actions that fall short of promoting these human values. Yang (2006) indeed argued that Kant's moral consistency provides an undivided and lucid criterion on how actions can be morally adjudicated. Yang affirms:

Moral requirements have a special status in human life....If one who has moral sentiments at all fails to act on them, one will feel guilty, regretful, or ashamed. Moral requirements are the most demanding... standards for conduct, for interpersonal and intercultural criticism (pp. 127-128).

The Kantian value is crucial as it preserves and protects the humanistic values in business. Clearly, the Kantian approach forbids and objects purely egoistic business measures and radical relativism in business. Kant's imperative values uphold the interests of stakeholders and argues that business relativism cannot dilute the inherent rights and interests of the stakeholders. Of course, the Kantian value is not without limitations. Finding a set of universally accepted moral rules is "ideal" but unrealistic. Different cultures, religion and background of a society decisively vary interpretations of moral values. Indeed, no moral principles can assume an absolute representation of a universal standard for all. The values of morality can and do change. Consider the contextual concerns of child labour. The International Labour Organisation (ILO) was fundamentally established with a sanctified and morally charged mission of eradicating all forms of child labour. ILO met fervent refutations from developing states and powerful corporations. Later, the ILO later accepted that child labour is relatively linked to a nation's poverty and cultural roots making it impossible to impose a universal ban. After much struggle and debate, the ILO changed from a universal ban to a more nuanced approach of prohibiting only the worst forms of child labour (with exceptions to agricultural sector). This of course includes slavery, prostitution, debt bondage and pornography or any other sectors or works that are deemed to harm the health, moral values and safety of children (Michelle, 2004). Nike took advantage on this contextual variability. Nike defended its child labour exploitations by arguing it was then necessary within context as it seeks to improve employment in those 
countries that it exploits.

Utilitarianism on the other hand, propounded by Bentham (1748-1832) and Mill (1806-1973) connotes that one should always act to produce the greatest ratio and balance of good (pleasure) over pain (sufferings). As a consequentialist proposition, an action would be deemed moral if an act produces the greatest value of pleasure for the greatest number of all. Sinnot Armstrong (2011), correctly states that utilitarianism measures the validity and morality of an act wholly dependent on the "consequences as opposed to the circumstances or the intrinsic nature of the act or anything that happens before the act". There are of course two immediate attractions of utilitarianism. Firstly, utilitarianism is inextricably linked to self-interests, invariably propels the economic success of the society. Adam Smith in the Wealth of Nation (1776) precisely articulates the correlation between utility and capitalism that:

pursuing his self-interest, he frequently promotes that of the society more effectually than when he really intends to promote it (Wealth of Nation, 1776).

Secondly, utilitarianism provides a very straightforward basis for evaluating policies and decisions. An action is deemed moral and valid if the consequences of the actions produce more pleasure as oppose to pain. The third appeal of utilitarianism (sharply in contrast with universalism) lies in its flexibility and ability to adjudicate a particular action. Recognising there is no intrinsic right or wrong, utilitarians invite organisations to resort to creative problem solving and innovation as long as the results and outcomes are pleasurable.

The foregoing review illustrates a stark difference between the moral standards of universalism and utilitarianism. There appears an unbridgeable gap between the two diversity of moral values. Due to this immense difference on moral dichotomy, authors generally agree that it becomes impossible or at least near impossible to reconcile these moral controversies. Shaw (2013) explains these moral contradictions where he mentioned:

Theoretical controversies permeate the subject of ethics and, as we have seen, philosophers have proposed rival ways of understanding right and wrong. These philosophical differences in perspectives, emphasis and theory are significant and can have profound practical consequences.... but obviously it cannot settle all of the questions that divide moral philosophers... (p. 92) [Emphasis added]

This paper on the contrary argues that the division and dichotomy between universalism and utilitarianism is not absolute. The inextricable and invariable link between the two theorems is observable when business firms that initially undertake a utility value later turns universalistic. Firms are naturally expected to exert a utility value when they make business decisions. However, there are occasions where these firms become irrepressibly relative and breach the minimum content of universal moral values. This in turn results in social, political and legal repercussions that might reset the firm to observe absolute moral values. The authors term this as the punctuated equilibrium.

In economic terms, punctuated equilibrium describes a sudden and radical change within a brief period of time subsequently followed by long period of stasis. Firms are generally relativists. However, firms can sometime behave overwhelmingly relative. They can breach the minimum threshold of morality. This can result in a tsunamic aftermath which inexorably turns the firm Kantian. This is lucidly witnessed where Shell Inc. came under fire in 1998 when the firm mishandled the Brent Oil Spar storage buoy saga in the Atlantic. It led to furious backlash from the public causing massive drop in share prices and distorted brand image. We can gauge the degree of Shell's repentance from the saga where its annual report writes:

We believe that we acted honourably in both cases. But that is not enough. Clearly, the conviction that you are doing things right is not the same as getting them right. For us at least, this has been a very salutary lesson. We were ready to learn from experiences, however painful, because of a planned process of change begun in 1994. It represented the most thorough and far reaching review for over 30 years-our Transformation. Nothing was sacrosanct and fundamentals were questioned: the structure, the way business is done, the quality of leadership, relationships with people and our vision of the future (Shell Inc. Annual Report, 1998). [Emphasis added]

The highlighted words and phrases are important. They signified two fundamental points. Firstly, Shell was deeply remorseful over the incident. The phrases "very salutary lesson" and "however painful" connote the punctuated aftermath of the incident on Shell. Secondly, it indicates Shell turned Kantian post the traumatic incident. One can see this where Shell writes, "most thorough far reaching-our transformation" where "fundamentals were questioned, including the "structure", "way business is done", "quality of relationships" and even Shell's "vision for the future". These remarks signified that the punctuated aftermath has reset of moral 
values in Shell with markedly greater emphasis on the goodwill of their actions post the Brent Oil Spar saga.

\section{Approach to Study}

In light of this complexity and understanding that ethics is not a linear but complex equation, the authors prefer to use a qualitative approach for this paper. Whilst quantitative research and samplings are analysed through mathematical and statistical correlation and coefficient between variables, qualitative data is more on observing a pattern matching (Eisenhardt, 1989). This is fundamental because business organisations are generally considered as artefacts that are socially intertwined with human activities and contextual interpretations. This basically mean that organisations do not exist in vacuum but there lies a constant nexus and inter connection with the society and community at large. Therefore, it becomes relatively necessary to analyse and examine ethics process by relating it to the organisational character and the context it is in (Basu \& Palazo, 2008).

Basu \& Palazo (2008), argue that a particular pattern of behaviour is more likely to occur as a result of its strong links with cognitive, linguistic, and behavioural features that define character and pattern of a firm's social behaviour. Upon considering the enterprise as socially-constructed artefact, the fundamental presumption is that organisations are intertwined in the open social and capitalist systems and are therefore coerced to recurring confrontation between socioeconomic complexities and practical realities. Also, organisations do not exist in an environment of certainty but far from it, business environment appears to be turbulent and evolving. Firms are inherently dragged into the constant conflict of polarised priorities and ideologies. Therefore, qualitative study becomes indissolubly important in rendering a multi-dimensional analysis and depicting a story telling mode towards a complete analysis of organisational characters.

This paper is based wholly on secondary data and the authors usurp a semantic and hermeneutical analysis of annual reports to discern patterns within the organisation studied. A firm's annual report provides a good qualitative and rhetorical study as it reflects an approximate barometer of the firm's level of understanding on moral values. A firm's annual and sustainability reports are generally an accurate means to assess corporate activities and to examine the company's engagements with stakeholders (Abrahamson \& Amir, 1996). Companies often reflect these management trends in their discourses, especially in their annual and sustainability reports.

For example, the Chief Executive Officer's (hereinafter referred to as the CEO) statements often define the companies' strategic lines. It is also considered as one of the most representative sections of the reports. Annual reports generally discuss corporate strategies and visions. Annual reports also transcript the firm's moral values. An examination and cross analysis of these reports may provide possible insights on how firms interpret moral values. This is often referred to as ethnography and rhetoric analysis.

However, rhetoric and hermeneutical study should be clearly distinguished from descriptive case study methods. Case studies are outward looking research methods that provide descriptive extrapolation and cognitive comparison with other case studies aimed at establishing discernible cross patterns and familiar trends. Case studies are capable of infusing internal and external validity of data. It postulates both the causal and nexus of interactions between recurring trends and common replications of logic in multiple case comparisons (Yin 1994). Ideally, case studies are essentially phenomenological providing a critical reflection on conscious rather than sub-conscious experience (Jopling, 1996).

On the contrary, ethnographies and rhetoric study are more inward looking. The significance lies within the anthropological and contextual values of the study. It hermeneutically analyses the interpretive meanings of semantics and text - analogue (Radnitzky, 1970). It contributes to uncover the sub conscious causes underlying the pattern of coherence (Taylor, 1976) by scrutinising the cultural role and unwritten conventions which mould behaviours and influences a firm's responses to exigencies. It also attempts to decipher the extent of purposive meanings beyond descriptive and literal information. Hence the qualitative study in this paper will be conducted using rhetorical study or hermeneutics. The term hermeneutics is described by Schutz (1953) as the second-level constructs. It measures the constructs perpetuated by the actors on the social scene or where one tries to interpret an exigency according to social norms and values.

A hermeneutical approach in studying moral values attempts to analyse statements made by firms' top management personnel. It also gauges the level of understanding, trend and importance of ethics within those firms examined. Hence, qualitative study is perceived to be capable of painting a multivariate exploration depicting approximate interactions between firms and its externalities.

The value of annual reports as a rhetoric analysis in turn rests on two basic assumptions. Firstly, there is an assumption that enterprises are social artefacts. Corporations are often entangled with socio-political 
confrontations and complexities (Daft, 1984). Secondly, annual reports transcribe a collective effort of the business firm to achieve moral values. Annual and sustainability report expresses the imprints of organisations' cognitive systems and transcripts actions into words. The reports signify an approximately unanimous opinion. It relates corporate moral objectives with a firm's contextual interpretation of its externalities (Hedberg, 1981).

\section{Drawing the Difference? The Volkswagen Experience}

For this paper the authors examine Volkswagen's (hereafter referred to as VW) responses towards the "diesel dupe" in 2015. This involves the installation of defeat device into car engines. The authors critically scrutinise the hermeneutics and semantical expressions in the $2016 \mathrm{VW}$ annual report. The selective study of VW is appropriate simply because of the magnitude of the scandal. VW suffered a staggering $€ 1$.7-billion-dollar losses due to recalls. Approximately 11 million owners are affected by the scandal. Also, VW case portrays a precise illustration on how the firm's punctuated equilibrium may reset the value of firm and henceforth transforming it into an absolute devotion to Kantian values. We begin by asking a few questions.

What was impact of the scandal on VW? How could one describe the magnitude of this impact? Clearly, the scandal has a deep and profound impact on VW. An excerpt of the 2016 annual report states the impact precisely:

Dear Readers and Colleagues, these are not normal times for Volkswagen.... But now we are back on schedule, so to speak.... However, this does not mean that everything is back to normal at our Company. There is no question that in terms of corporate responsibility, dealing with the repercussions of the diesel crisis is still one of our top priorities...... (VW Annual Report, 2016, p. 8) [Emphasis added]

The phrase "these are not normal times for Volkswagen" is an unusual description. Regular annual reports do not normally express such solemnity. This phrase clearly demarcates VW's sombreness and clearly illustrates the grave impact the scandal had on VW. A similar connotation is found elsewhere in the report:

"We deeply regret the behavior that gave rise to the diesel crisis. Such misconduct runs contrary to all the values that Volkswagen stands for" (VW Annual Report, 2016, p. 27) [Emphasis added].

Evidently, VW appears deeply apologetic. The phrase sub consciously but explicitly displayed the reparation that VW had towards the scandal. This is fortified elsewhere in the interview with Hans Dieter pötsch, Chairman of the Supervisory Board where he states:

How long will it take until the company is able to leave the diesel crisis behind it? "I can't give you an exact time period - but it will take us quite a while. Serious mistakes were made at Volkswagen. We have already paid dearly for them, and we remain committed to taking responsibility for our actions...." (VW Annual Report, 2016, p. 27) [Emphasis added].

Two immediate deductions from these excerpts are possible. Firstly, the impact of the scandal goes to the core of VW values. The annual report expressed it to be a deeply regretted event. Secondly, the magnitude of the scandal is austere as VW appears to have paid dearly for the scandal. The serious mistakes have substantially distorted the image of VW which might take VW indefinite time to leave the diesel crisis behind. These points quite accurately indicate that the scandal is serious and poses a tsunamic impact on VW. This may have in fact triggered a punctuated equilibrium on VW.

The second question is of course whether VW has turned Kantian post the traumatic impact following the scandal? Has that punctuated equilibrium steered VW towards a more Kantian exaltation? What are the indications thereof? To answer this question, the authors will assess if VW fulfils the three notions of Kantian values. The first question is of course whether VW has established an indivisible moral maxim? We perhaps can attain a glimpse of this emerging Kantian values in one of the excerpt where it clearly states:

This makes it all the more essential for us to establish a solid framework of values, in the form of our renewed commitment to sustainable, responsible business practices (VW Annual Report, 2016, p. 8) [Emphasis added]

Again, the emphasised phrases provide cogent clues on this intended transformation. It appears that the scandal provides an essential catalyst for VW to provide a solid framework of values. The term solid framework of values probably signifies VW's commitment to constitute a more categorically imperative and non-negotiable moral values. This clearly implicates a retreat from relativism in the firm. Also, the term "renewed" used in this excerpt could also bear significant resemblance of a possible reset of VW corporate values. This notion of moral reset is further fortified elsewhere in the report where it states:

As we pursue this radical transformation, our managers bear special responsibility - they must lead by example and work closely with their teams to bring about this sweeping cultural change (VW Annual 
Report, 2016, p. 8) [Emphasis added]

The excerpt above gives good light in answering the question we raised earlier. How far fetch is this Kantian transformation? It appears that VW's transition to Kantian moral maxim is firm and committed since VW anticipates a "radical transformation" and sub-consciously describes it as a "sweeping cultural change". This clearly indicates that VW has reset and refresh its core moral values post the scandal attuning to a more immutable Kantian values.

Has VW exhibited goodwill? Interestingly, VW again sub-consciously expressed this good will and committed approach in page 7 of the report where it clearly expressed the following:

We will do everything in our power to prevent incidents of this kind from reoccurring, and are fully committed to re-embracing our standards and winning back public trust (VW Annual Report, 2016, p. 7) [Emphasis added]

This is a striking excerpt. Clearly, VW expressed an unwavering stance to prevent this kind of incidents recurring and VW expressed total unfettered pledge to reenergise their moral values and to regain the trust of the stakeholders. That gives a very lucid indication that VW embraced a non-contradictory and purely good will approach to ending this saga.

The final question is whether the purported approaches of moral reclamations that VW undertakes are purportedly designed for universal acceptance? Clearly, in page 19 of the report, VW provides clear directions on stakeholder management. Page 19 of the report reads:

Around the globe, we are confronted with a broad spectrum of stakeholder requirements, expectations and attitudes on a daily basis. The enormous diversity of our interactions is invaluable to the work we do. At the same time, this diversity of interests is also a challenge, because it can result in conflicting objectives (VW Annual Report, 2016 p. 19) [Emphasis added].

This excerpt of course fortifies the Kantian's weakness of seeking an ideal and universal set of moral values. We can see that VW faced this dilemma of searching this holy grail. Despite this challenge, further excerpts from the report protrudes VW's ardent search for this idealistic and universal moral value. In page 19, VW clearly indicates that the all stakeholders are of equal importance and makes no attempt to prioritise their values where it states:

Based on our regular contacts, we have identified twelve additional stakeholder groups surrounding this core, which we make no attempt to prioritize (VW Annual Report, 2016) [Emphasis added].

This notion is fortified elsewhere in page 21 where it states:

We will only be successful in the long term if we familiarize ourselves thoroughly with the interests, needs and expectations of our stakeholders and deal with them proactively. To successfully facilitate a dialog of equals ... (VW Annual Report, 2016) [Emphasis added].

The two excerpts above quickly serve one essential point. VW strives to collate all views and to engage in equal dialogs with the stakeholders. This evidences VW's focused effort to ascertain universal agreement to their business models. The fact that VW makes no attempt to prioritise the stakeholders too indicate that VW intends to establish unbiased and universal moral values.

\section{Implications for Corporations}

This paper provides an unorthodox paradigm on the inextricable link between utilitarianism and universalism. This paper does not challenge previous ideas and notions that these two theorems in ethics are starkly distinct and they remain to be distinct for a simple purpose of categorising business ethics. However, this paper maintains that despite the unembellished distinctions between the two concepts they can be inextricably linked in context. While it is a common and regular assumption that business firms normally usurp a utilitarian business value, firms are estopped in protruding that value when they breach the minimal content of morality. That would result in a punctuated equilibrium which in turn forward serious business repercussions for the firm. Most firms will respond by resorting to embrace universalistic and categorically imperative moral values. This anticipation is clearly seen in some firms such as Shell and VW where their annual reports consciously and sub-consciously implicate this inextricable link between utilitarianism and universalism in context. However, not all firms face punctuated equilibrium. Some firms face incremental pressures which fall short of punctuated momentum. Firms do not normally experience a reset of moral values in these conditions. Not all external pressures are sufficient to generate a tsunamic impact on a firm. The responses of a firm towards the punctuated aftermath is also equally important. VW displayed an "open posture" when tackling the moral challenge. Firms may on the contrary 
display "defensive posture". Consider United Airlines "messed up" initial response on the incident which involved dragging a passenger off the plane on 9th April 2017. A defensive posture potentially delays the "reset" processes, drags the firm into deeper entangled conflicts.

\section{Acknowledgments}

Special thanks to my colleagues and peers that co-authored this paper. Your views and critiques are invaluable and very much appreciated.

\section{References}

Abrahamson, E., \& Amir, E. (1996). The information content of the president's letter to shareholders. Journal of Business Finance and Accounting, 23(8), 1157-1183. https://doi.org/10.1111/j.1468-5957.1996.tb01163.x

Basu, K., \& Palazzo, G. (2008). Corporate Social Responsibility: A Process Model of Sensemaking. Academy of Management Review, 33(1), 122-136. https://doi.org/10.5465/AMR.2008.27745504

Carr, A. Z. (1968). Is Business Bluffing Ethical? Harvard Business Review, 46(1), 146.

Daft, R. L. W., \& Karl, E. (1984). Toward a model of organizations as interpretation systems. Academy of Management Review, 9(2), 284-295.

Hedberg, B. (1981). How Organizations Learn and Unlearn. In P. Nystrom \& W. Starbuck (Eds.), Handbook of Organizational Design, 1, 3-27. Oxford: Oxford University Press.

Jopling, D. (1996). Sub-phemenology. Human Studies, 19(2), 153-173. https://doi.org/10.1007/BF00131491

Michele, D. (2004). Child Labor and Cultural Relativism: From 19th Century America to 21st Century Nepal, PaceInt'IL. Rev. 109. Retrieved from http://digitalcommons.pace.edu/pilr/vol16/iss1/5

Radnitzky, G. (1970). Contemporary Schools of Metascience. Göteborg: Scandinavian University Books.

Rolf, M. (2010). Immanuel Kant. The Stanford Encyclopedia of Philosophy. E. N. Zalta (Ed.). Retrieved from http://plato.stanford.edu/entries/kant/

Schutz, A. (1964). The Social World and the Theory of Social Action. In A. Brodersen (Ed.), His Collected Papers II: Studies in Social Theory. The Hague: Martinus Nijhoff. https://doi.org/10.1007/978-94-017-6854-2_1

Shaw, W. H., Barry, V., Issa, T., \& Catley, B. (2013). Moral Issues in Business (2nd Asia Pacific ed.). Australia: Cengage Learning.

Shell Annual Report. $\quad$ (1998). $\quad$ Retrieved from http://www.shell.com/sustainability/sustainability-reporting-and-performance-data/sustainability-reports/pre vious/_jcr_content/par/expandablelist/expandablesection_332888471.stream/1454157664246/7419d7c0b96 ee36e92059e205107e3106d35d9d8f3a4909c8523f49ded9e4727/shell-sustainability-report-1998-1997.pdf

Sinnott, A. W. (2012). Consequentialism. The Stanford Encyclopedia of Philosophy. E. N. Zalta (Ed.). Retrieved from http://plato.stanford.edu/archives/win2012/entries/consequentialism/

Taylor, C. (1976). Hermeneutics and politics. In P. Connerton (Ed.), Critical Sociology: Selected Readings. Middlesex: Penguin.

$\begin{array}{llll}\text { Volkswagen } & \text { Annual } & \text { Report. } & \text { (2016). }\end{array}$ https://www.volkswagenag.com/presence/investorrelation/publications/annual-reports/2017/seat/SEAT_201 6_ING.pdf

Weiss, J. W. (2009). Business Ethics: A Stakeholder \& Issues Management Approach. Mason, OH: South-Western Cengage Learning.

Yang, X. (2006). Categorical imperatives, moral requirements, and moral motivation. Metaphilosophy, 37(1), 112-129. https://doi.org/10.1111/j.1467-9973.2006.00419.x

Yin, R. K. (1994). Case Study Research (2nd ed.). London: Sage.

\section{Copyrights}

Copyright for this article is retained by the author(s), with first publication rights granted to the journal.

This is an open-access article distributed under the terms and conditions of the Creative Commons Attribution license (http://creativecommons.org/licenses/by/ 4.0/). 